\title{
Study and Analysis for the Choice of Optical Fiber in the Implementation of High-Capacity Backbones in Data Transmission
}

\author{
Wilmer Vergaray-Mendez ${ }^{1}$ \\ Facultad de Ciencias e Ingeniería \\ Universidad de Ciencias y \\ Humanidades \\ Lima, Perú
}

\author{
Brian Meneses-Claudio ${ }^{2}$ \\ Image Processing Research \\ Laboratory (INTI-Lab) \\ Universidad de Ciencias y \\ Humanidades, Lima, Perú
}

\author{
Alexi Delgado ${ }^{3}$ \\ Interdisciplinary Research Center \\ Science and Society (CIICS) \\ Universidad de Ciencias y \\ Humanidades, Lima, Perú
}

\begin{abstract}
Today, fiber optic implementation projects for backbones have become a necessity, where in many cases failures due to cable stress breaks have been reported. Due to this, it is necessary to carry out a study and analysis of the zone and area prior to implementation. In this research work, through a method based on theory and analysis, the geographical and climatological conditions where the optical fiber will be installed in the Lima region, Peru, will be evaluated, as well as the study of mechanical loads and electric fields associated with the installation of fiber optics on existing electrical network lines will also be carried out. The results of this study showed that for regional backbone projects in the city of Lima, Peru, the use of the type of optical fiber should be considered under the recommendation of the International Telecommunications Union (ITU) -T G.652.D All -Dielectric Self-Supporting (ADSS). The studies and results obtained in this research may also help the various companies in the sector, in future implementations of high-capacity fiber optic backbones in data transmission, to make the best decision on the type of cable and its recommended characteristics for the region.
\end{abstract}

Keywords-Mechanical loads; electric fields; backbones; optical fiber; data transmission

\section{INTRODUCTION}

Optical fibers constitute the central axis of the global telecommunications system, they were designed to transmit high information capacity [1]. The growing demand in speed of information transmission has made the implementation of fiber optics comply with national and international standards and recommendations [2]. The absence of orderly information and poor practices followed by empiricism in the choice and installation of fiber optics in the Lima-Peru region, have led to high numbers of expenses for operational maintenance of the network, as shown in Table I, because it is not considered the geographical and climatological factors and conditions of the Lima region, based on the National Electricity Code (CNE) [3]. That is why in the present research work, based on the CNE and considering the factors and conditions mentioned above, a study and analysis was carried out to choose the type of fiber optic suitable for installation in the Lima-Peru region.
Table I shows a comparative table in percentage of what the operators represent to carry out the maintenance of the fiber optic network with respect to the annual capex in Peru.

The optical fiber is resistant to deterioration and high temperatures, the protection of the coating is ideal to withstand high stresses in the installation, the optical fiber does not originate electromagnetic radiation, it is resistant to intrusive actions, to access the information that circulates in the fiber it is necessary to cut it, which there is no transmission of information during this process, and it is easily detectable, therefore it is a safe means of transmitting information [4]. However, a common problem that usually occurs when choosing the type of fiber optic cable is that an exhaustive analysis of the mechanical loads to which the cable will be exposed in the installation is not carried out, thus verifying the maximum allowable stresses of the fiber optic cable ADSS [5]. Due to this, the present research work will analyze the mechanical loads that affect the optical fiber when it is installed in the Lima-Peru region.

Choosing a fiber optic cable for any application implies considering in an analytical way the electric field levels produced by medium voltage lines in which they are installed to allow the network to be expanded throughout the entire national and international territory [6]. For the installation, it is necessary to consider where and how the cable will be installed, either in an underground conduit in an outside plant or in trays within a building. Requirements for long-term installations include humidity or exposure to water, temperature, tension in overhead cables, and environmental factors in the various areas of the region Perú [7].

TABLE I. COMParative Fiber OPtic NeTwork MaINTENANCE

\begin{tabular}{|l|l|l|}
\hline Year & G.652.D & Others \\
\hline 2020 & $6 \%$ of Annual Capex & $14 \%$ of Annual Capex \\
\hline 2019 & $7 \%$ of Annual Capex & $16 \%$ of Annual Capex \\
\hline 2018 & $9 \%$ of Annual Capex & $19 \%$ of Annual Capex \\
\hline
\end{tabular}


In the Thesis Design of a Broadband Network in the San Martin Region, Peru, Carlos Bedregal, indicates that fiber optic technology is an excellent means of transporting information, even more so through new scientific developments in the field of optics, which give it a high scalability factor in the present [8]. That is why the thesis presents as a highly effective and profitable alternative the implementation of fiber optics on existing electrical network infrastructure, to provide telecommunications services to many users, in addition to being able to comfortably support the increase of users in the future, without having to make new capital investments.

In the Thesis Design of a Fiber Optic Network for Broadband in Coishco, Ancash, Peru, Elliot Lopez, recommends the use of fiber optic cable that complies with the ITU-T G.652.D [9], due to the fact that long distance communication systems are optimal for solutions, a main characteristic is the high transmission capacity due to the increase in bandwidth, it allows reaching up to $3000 \mathrm{~km}$ and 40 $\mathrm{km}$ of distance at speeds of $10 \mathrm{Gbps}$ and 40 Gbps respectively without regenerations, it is also ADSS type, essential for installation on infrastructure of medium and low voltage power lines. [10].

In [5], it mentions that the fiber optic ITU-T G.652.D presents an optimal performance in the operation of the transmission equipment of the highest range Dense Wavelength Division Multiplexing (DWDM) according to manufacturer's NEC, Huawei, Alcatel Lucent and other fiber optic providers, likewise, it does not present disadvantages compared to other types of optical fibers such as G.655 and G.656. Optical fiber under ITU-T Recommendation G.652.D is designed for high-capacity backbone networks and operates with DWDM technology from leading DWDM equipment manufacturers.

The increasing requirement for capacity and speed in the transmission of information has made fiber optics the preferred transmission medium in the construction of physical communication links [2], that is why the objective of this research article is oriented in the study and analysis of the various factors, such as geographical and climatological conditions that the Lima region presents, in order to choose the type of optical fiber with specific characteristics for certain areas of the Lima region, Peru, to achieve this a series of hypotheses is considered for the various areas that the region presents, all this analysis is carried out based on the standards and norms that include the design, manufacture, installation and testing of fiber optics [11]. The Lima-Peru region is specifically considered for its geographical areas that are in rugged areas, difficult to access, extreme and variable climates as shown in Fig. 2, where the analysis of mechanical loads and electric fields can be carried out, which are considered as a fundamental part in the research work, since transmitting high information capacity requires that the physical environment be as optimal as possible.

The study and analysis of the geographical and environmental conditions were analyzed with the help of the National Electricity Code, which describes the characteristics of the various zones and load areas of the Lima region, Peru, after that to acquire the values of electric field produced by medium and low voltage lines, the calculation software Electric Field of Transmission Lines (EFT), an application of the Electric Power Research Institute (EPRI), was used.

This research work is structured as follows: In Section II, the theoretical description, types, and characteristics of the fiber optic cable will be shown, as well as the technical standards associated with it. In Section III, the study and analysis for the choice of optical fiber will be shown, where the mechanical loads and electric fields to which the optical fiber will be exposed at the time of installation are described. In Section IV, the results obtained when carrying out the analysis and study of the calculations of mechanical loads and electric fields will be shown. In Section $V$, the discussions of the research work are presented and finally in Section VI, the conclusions, as well as the recommendations of the future research that will be achieved with this article.

\section{OPTICAL FIBER}

\section{A. Types of Fiber Optics}

According to the number of modes of propagation of the light ray, an optical fiber is classified into single-mode and multimode, both of which have a diameter of $12 \mu \mathrm{m}$ coating. The ITU defines six operating bands for single-mode optical fiber, according to wavelength $(\lambda)$ : Original $(\mathrm{O})$, Extended $(\mathrm{E})$, Short wavelength (S), Conventional (C), Long wavelength (L), Ultra wavelength (U), as shown in Fig. 1 [5].

1) Multimode optical fibers: Multimode optical fibers, on the other hand, have a diameter of $9 \mu \mathrm{m}$. They can transmit several light rays by successive reflections, this being their main limitation for their consideration in the design of backbones networks [5].

2) Single-mode optical fibers: Single-mode optical fibers have a core that varies from 7 to $11 \mu \mathrm{m}$, due to their special design they have the ability to send a single mode of light, understood as "light mode" to a "light ray" in theory only allows the propagation of a straight-line light mode using a high intensity laser cannon, furthermore, they allow reaching long distances and high data bit rates [5], as shown in Table II.

Table II shows the $\mathrm{OM}^{*}$ nomenclature according to the Telecommunications Industry Association (TIA), B* nomenclature according to the International Electrotechnical Commission (IEC), G* nomenclature according to the International Telecommunications Union (ITU) [12].

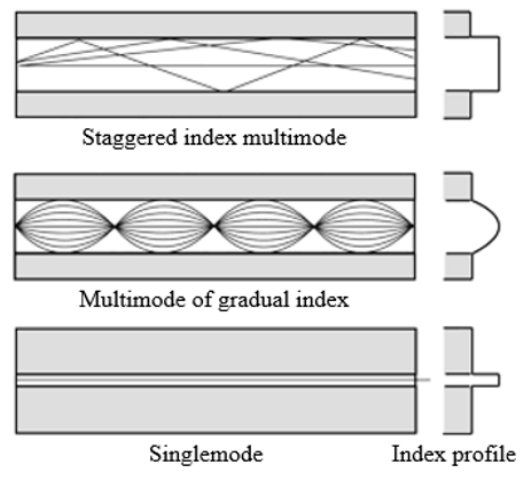

Fig. 1. Types of Optical Fiber. 
TABLE II. TYPES OF OPTICAL FIBER AND SPECIFICATIONS

\begin{tabular}{|c|c|c|c|}
\hline Core/Coating & $\begin{array}{l}\text { Atten } \\
\text { uation }\end{array}$ & $\begin{array}{l}\text { Bandwidt } \\
\text { h }\end{array}$ & Applications/Notes \\
\hline Multimode & $\begin{array}{l}850 / 13 \\
00 \mathrm{~nm}\end{array}$ & $\begin{array}{l}\text { 850/1300 } \\
\mathrm{nm}\end{array}$ & \\
\hline $\begin{array}{l}50 / 125 \text { microns } \\
\text { (OM2) }\end{array}$ & $\begin{array}{l}3 / 1 \\
\mathrm{~dB} / \mathrm{km}\end{array}$ & $\begin{array}{l}\text { 500/500 } \\
\text { MHz-km }\end{array}$ & For lasers for GbE LAN networks \\
\hline $\begin{array}{l}50 / 125 \text { microns } \\
\text { (OM3) }\end{array}$ & $\begin{array}{l}3 / 1 \\
\mathrm{~dB} / \mathrm{km}\end{array}$ & $\begin{array}{l}\text { 2000/500 } \\
\text { MHz-km }\end{array}$ & Optimized for $850 \mathrm{~nm}$ VCSEL \\
\hline $\begin{array}{l}\text { 50/125 microns } \\
\text { (OM4) }\end{array}$ & $\begin{array}{l}3 / 1 \\
\mathrm{~dB} / \mathrm{km}\end{array}$ & $\begin{array}{l}\text { 4700/500 } \\
\text { MHz-km }\end{array}$ & $\begin{array}{l}\text { Optimized for } 850 \mathrm{~nm} \\
\text { VCSEL }>10 \mathrm{~Gb} / \mathrm{s}\end{array}$ \\
\hline $\begin{array}{l}62.5 / 125 \\
\text { microns (OM1) }\end{array}$ & $\begin{array}{l}3 / 1 \\
\mathrm{~dB} / \mathrm{km}\end{array}$ & $\begin{array}{l}160- \\
200 / 500 \\
\text { MHz-km }\end{array}$ & Fiber for LAN (FDDI) \\
\hline $100 / 140$ microns & $\begin{array}{l}3 / 1 \\
\mathrm{~dB} / \mathrm{km}\end{array}$ & $\begin{array}{l}\text { 150/300 } \\
\text { MHz-km }\end{array}$ & Obsolete \\
\hline Single mode & $\begin{array}{l}1310 / 1 \\
550 \mathrm{~nm}\end{array}$ & $\begin{array}{l}\text { 1310/155 } \\
\text { Onm }\end{array}$ & \\
\hline $\begin{array}{l}\text { 9/125 microns } \\
\text { (OS1, B1.1, or } \\
\text { G.652) }\end{array}$ & $\begin{array}{l}0.4 / 0.2 \\
5 \\
\mathrm{~dB} / \mathrm{km}\end{array}$ & $\sim 100 \mathrm{Tz}$ & $\begin{array}{l}\text { Telecommunications / Cable TV, } \\
\text { long distance, and high-speed LAN } \\
\text { networks }\end{array}$ \\
\hline $\begin{array}{l}\text { 9/125 microns } \\
\text { (OS2, B1.3, o } \\
\text { G.652) }\end{array}$ & $\begin{array}{l}0.4 / 0.2 \\
5 \\
\mathrm{~dB} / \mathrm{km}\end{array}$ & $\sim 100 \mathrm{Tz}$ & "Low Water Peak" (LWP) Fiber \\
\hline $\begin{array}{l}\text { 9/125 microns } \\
\text { (B2, or G.653) }\end{array}$ & $\begin{array}{l}0.4 / 0.2 \\
5 \\
\mathrm{~dB} / \mathrm{km}\end{array}$ & $\sim 100 \mathrm{Tz}$ & Dispersion Shifted Fiber (DSF) \\
\hline $\begin{array}{l}\text { 9/125 microns } \\
\text { (B1.2, or G.654) }\end{array}$ & $\begin{array}{l}0.4 / 0.2 \\
5 \\
\mathrm{~dB} / \mathrm{km}\end{array}$ & $\sim 100 \mathrm{Tz}$ & Cut-off Shifted Fiber (CSF) \\
\hline $\begin{array}{l}\text { 9/125 microns } \\
\text { (B4, or G.654) }\end{array}$ & $\begin{array}{l}0.4 / 0.2 \\
5 \\
\mathrm{~dB} / \mathrm{km}\end{array}$ & $\sim 100 \mathrm{Tz}$ & $\begin{array}{l}\text { Non-zero dispersion-shifted fiber } \\
\text { (NZ-DSF) }\end{array}$ \\
\hline
\end{tabular}

3) Technical standards

- Código Nacional de Electricidad, Perú (CNE) Reglas 250.B, 250-C, Tabla 235-5 [3].

- Institute of Electrical and Electronics Engineers (IEEE) Std 1222-2011, Standard for Testing and performance for ADSS Fiber Optic Cable for Use on Electric Utility

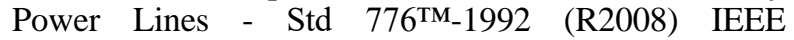
Recommended Practice for Inductive Coordination of Electric Supply and Communication Lines - Std $1137^{\text {TM}}$-1991 (R2008) IEEE Guide for the Implementation of Inductive Coordination Mitigation Techniques and Application [13].

- Resolución Ministerial-368-2011-MTC / 03, Working Document "Especificaciones Técnicas para el Tendido de Fibra Óptica en Redes de Energía Eléctrica y de Hidrocarburo" [14], [15].

- Single-mode ADSS fiber optic cable data sheets, span 250, 600, 1000 and 1200 [16].

\section{METHODOLOGY}

\section{A. Recommendation ITU-T G.652}

It is a standard single-mode optical fiber with non-shifted dispersion, it was initially optimized for use in the $1310 \mathrm{~nm}$ wavelength region, but it can also be used in the $1550 \mathrm{~nm}$ region, it presents "zero" dispersion $\left(0.092 \mathrm{ps} / \mathrm{nm}^{2} * \mathrm{~km}\right)$ in the second window at $1300 \mathrm{~nm}$ to $1324 \mathrm{~nm}$, it is suitable for Coarse Wavelength Division Multiplexing (CWDM), it can be used in the second window with worse attenuation at 0.4 $\mathrm{dB} / \mathrm{km}$ or in the third window with worse dispersion, but can be improved with compensating devices dispersion [9]. The ITU-T G.652 recommendation has four variants A, B, C and D. The G.652 A and B optical fibers were the first to be marketed, but they were discontinued because they presented high attenuation in the 1390nm band (E band), phenomenon known as "water peak", which was corrected in later versions G.652 C and $\mathrm{D}$, with this optimization the $\mathrm{E}$ band can be fully exploited.

In this research, emphasis is placed on the use of fiber optic cable manufactured based on the recommendations of ITU-T G.652.D, because its characteristics are the best option for installation in geographic areas of the Lima region; below in Table III the most outstanding is described:

TABLE III. CHARACTERISTICS OF THE ITU-T G652.D FIBER OPTIC

\begin{tabular}{|c|c|c|}
\hline Description & \multicolumn{2}{|l|}{ G.652.D } \\
\hline \multirow{2}{*}{ Modal Field Diameter (mm) } & $1310 \mathrm{~nm}$ & $9.2 \pm 0.4$ \\
\hline & $1550 \mathrm{~nm}$ & $10.3 \pm 0.5$ \\
\hline \multirow{3}{*}{ Attenuation Coefficient $(\mathrm{dB} / \mathrm{Km})$} & $1310 \mathrm{~nm}$ & $\leq 0.35$ \\
\hline & $1383 \mathrm{~nm}$ & $\leq 0.35$ \\
\hline & $1550 \mathrm{~nm}$ & $\leq 0.24$ \\
\hline \multirow{2}{*}{ Chromatic Dispersion (ps/nm. Km) } & $1285-1330 \mathrm{~nm}$ & $\leq 3$ \\
\hline & $1550 \mathrm{~nm}$ & $<18$ \\
\hline Zero Dispersion Wavelength (nm) & \multicolumn{2}{|l|}{$1300-1322$} \\
\hline Zero Dispersion Slope (ps / nm2 Km) & \multicolumn{2}{|l|}{$\leq 0.092$} \\
\hline \multirow{2}{*}{ Refractive Index } & $1310 \mathrm{~nm}$ & 1.467 \\
\hline & $1550 \mathrm{~nm}$ & 1.468 \\
\hline Cut Wavelength (nm) & Cabling & $\leq 1260$ \\
\hline PMD (ps / (ps/ $/ \sqrt{ }$ m) Link Value & $1550 \mathrm{~nm}$ & $\leq 0.1$ \\
\hline Mechanical Specifications & \multicolumn{2}{|l|}{ G.652.D } \\
\hline Core non-circularity & \multicolumn{2}{|l|}{$\leq 6 \%$} \\
\hline Core / cladding concentricity error & \multicolumn{2}{|l|}{$\leq 1 \mathrm{~mm}$} \\
\hline Cladding diameter & \multicolumn{2}{|l|}{$125 \pm 1 \mathrm{~mm}$} \\
\hline Cladding non-circularity & \multicolumn{2}{|l|}{$\leq 1 \%$} \\
\hline Primary coating diameter & \multicolumn{2}{|l|}{$245 \pm 10 \mathrm{~mm}$} \\
\hline Primary coating non-circularity & \multicolumn{2}{|l|}{$\leq 6 \%$} \\
\hline Primary coating concentricity error & \multicolumn{2}{|l|}{$\leq 12.5 \mathrm{~mm}$} \\
\hline Proof Test & \multicolumn{2}{|c|}{$\geq 8.8 \mathrm{~N} / \geq 1 \% / \geq 100 \mathrm{Kpsi}$} \\
\hline
\end{tabular}

\section{B. Study of Mechanical Loads of Fiber Optic Cable}

The study and analysis to be carried out in this article is based on the CNE, where we will carry out an exhaustive analysis with different hypotheses considering the best and worst geographical, environmental and climatological conditions for the choice of the type of Optical fiber to be used in the implementation of a backbone network for transmission of high capacity information, those are detailed in Table VI and 
VII [17], which is in the order superior to Gb/s. According to the CNE, the Lima region is located in Zone B, Loading Area 0, 1, 2 and 3, as shown in Fig. 2; which for the purposes of the study will only take specific data and has been classified by Cluster 1 and 2 (North) and Cluster 3 and 4 (South) [3], as described in Tables IV and V.

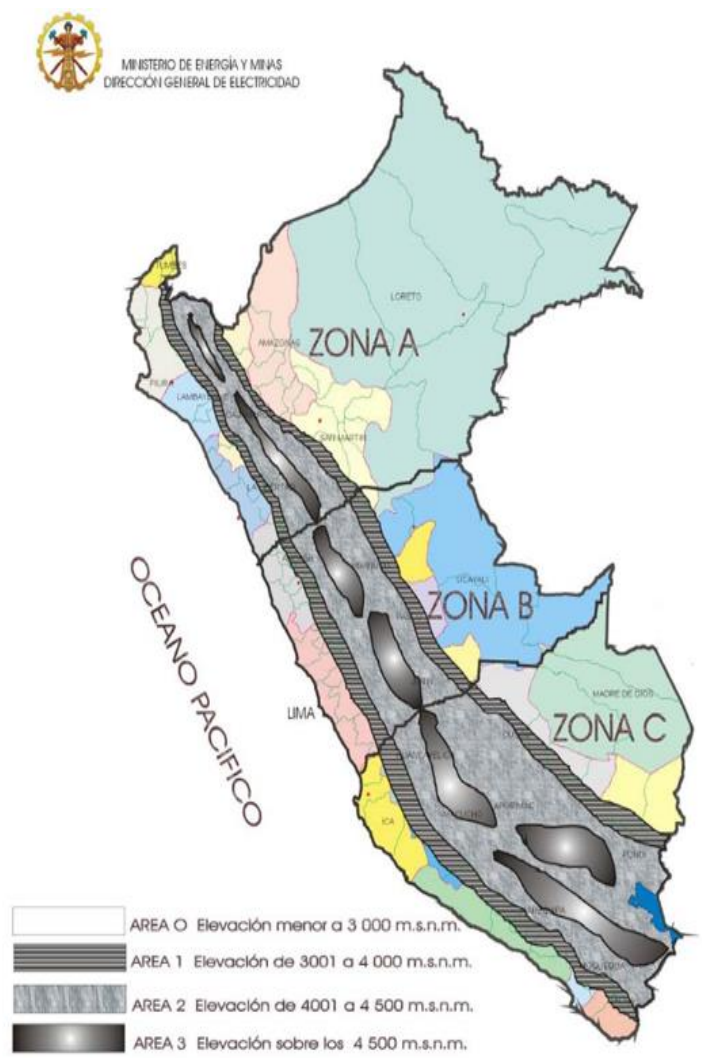

Fig. 2. Location of Load Areas in Peru.

The purpose of this calculation is to verify the maximum admissible stresses of the fiber optic cable ADSS span 250, 600 and 1200, for its subsequent implementation in existing and projected electrical networks, which is part of this study article [5] The calculations will be modeled taking into consideration the recommendations given in the CNE [3], and the techniques of FiberHome, manufacturer of the fiber optic cable [16].

\section{1) Geographic location of cluster 1 and 2}

TABLE IV. FibER OPTIC SECTIONS

\begin{tabular}{|l|l|l|l|l|}
\hline SECTION A-B & $\begin{array}{l}\text { PROVIN } \\
\text { CE }\end{array}$ & $\begin{array}{l}\text { START } \\
\text { DISTRICT }\end{array}$ & $\begin{array}{l}\text { FINAL } \\
\text { DISTRICT }\end{array}$ & $\begin{array}{l}\text { CLUST } \\
\text { ER }\end{array}$ \\
\hline SL09 - COPA & $\begin{array}{l}\text { CAJATA } \\
\text { MBO }\end{array}$ & HUNCAPON & COPA & 1 \\
\hline $\begin{array}{l}\text { OYON - } \\
\text { CHURIN }\end{array}$ & OYON & OYON & OYON & 1 \\
\hline $\begin{array}{l}\text { SAYAN - } \\
\text { HUMAYA }\end{array}$ & HUAURA & HUAURA & HUAURA & 2 \\
\hline $\begin{array}{l}\text { HUAURA - } \\
\text { HUMAYA }\end{array}$ & HUAURA & HUAURA & HUAURA & 2 \\
\hline ACOS - CARAC & HUARAL & ACOS & CARAC & 2 \\
\hline
\end{tabular}

2) Climatic characteristics: The climatological characteristics correspond to the study areas as stipulated in the CNE Section 25, Rules 250B and Table 250-1 [3].

TABLE V. LOCATION ACCORDING TO ZONE AND AREA

\begin{tabular}{|l|l|l|l|l|l|l|l|}
\hline Section & Zone & Area & Long & Start & Alt & End & Alt \\
\hline SL09 - Copa & B & 1,2 & 16635 & 1 & 3563 & 92 & 3368 \\
\hline Oyon - Churin & B & 0,1 & 25655 & 1 & 3702 & 236 & 2284 \\
\hline Sayan - Humaya & B & 0 & 25309 & 1 & 637 & 330 & 390 \\
\hline Huaura - Humaya & B & 0 & 23296 & 1 & 64 & 266 & 321 \\
\hline Acos - Carac & B & 0 & 11394 & 1 & 1853 & 37 & 2466 \\
\hline
\end{tabular}

3) Characteristics of the existing power line: For study and calculation purposes, the fiber optic cable to be analyzed has the projection to be implemented over the existing electrical network, considering a length of approximately 750 $\mathrm{km}$, being the following for each cluster: Cluster 1: $265 \mathrm{~km}$ and Cluster 2: $485 \mathrm{~km}$. The following main characteristics are considered:

- Nominal voltage: $10,13.2,22.9,60 \mathrm{kV}$.

- Maximum voltage: 11, 14.5, 25, $66 \mathrm{kV}$.

- Electric Company: Adinelsa, Enel, Coelvisac.

- Number of Circuits: Simple and double.

- Conductor arrangement: Vertical, horizontal, and triangular.

- Length: $510 \mathrm{~km}$.

- Active Conductor: 01 conductor per phase All Aluminum Alloy Conductors (AAAC) 35-120 mm².

- Structures: Concrete, metallic, fiber and wood posts.

- Types of Arming: Suspension, anchoring, and retention.

4) Mechanical calculation of the fiber optic cable: The mechanical calculations of the cable aim to determine the following relative magnitudes in all the analysis hypotheses:

- Horizontal force of the conductor.

- Tangential force of the conductor in the supports.

- Driver's arrow.

- Driver parameters.

- Exit angles of the conductor with respect to the horizontal line, in the supports.

- Span - weight of the structures.

- Span - middle of the structure. 


\section{5) Maximum stresses on the conductor}

a) Cable stress in Everyday Stress (EDS): The technical standards regarding the behavior of conductors recommend using the following horizontal effort as a reference:

- In the Everyday stress (EDS) condition $18 \%$ of the cable breaking stress according to good industry practices.

b) Maximum cable stresses: The maximum stresses in the cable are the tangential stresses that occur at the highest points of the catenary.

- For ADSS fiber optic cable, its value should not exceed $51 \%$ of the breaking stress. (Value given by the fiber optic cable manufacturer).

6) Calculation hypothesis: The state hypotheses for the mechanical calculations of the fiber optic cable are defined on the basis of the following factors, the same as those defined by the CNE [3], and the following hypotheses will be considered: Wind speed, temperature and ice load.

TABLE VI. ZONING, AREAS, AND LOADS

\begin{tabular}{|l|l|}
\hline Hypothesis 1 & Longer Duration Condition (EDS) \\
\hline Temperature & Average annual \\
\hline Wind speed & Null \\
\hline Ice overload & Null \\
\hline Hypothesis 2 & Minimum temperature condition \\
\hline Temperature & Minimum \\
\hline Wind speed & Null \\
\hline Ice overload & Null \\
\hline Hypothesis 3 & Maximum wind speed condition \\
\hline Temperature & Minimum \\
\hline Wind speed & Maximum \\
\hline Ice overload & Null \\
\hline Hypothesis $\mathbf{4}$ & Maximum ice load condition \\
\hline Temperature & Medium \\
\hline Wind speed & Null \\
\hline Ice overload & Maximum \\
\hline Hypothesis 5 & Maximum temperature condition \\
\hline Temperature & Minimum \\
\hline Wind speed & Null \\
\hline Ice overload & Null \\
\hline Hypothesis $\mathbf{6}$ & Wind and ice combine \\
\hline Temperature & Minimum \\
\hline Wind speed & Maximum \\
\hline Ice overload & Maximum \\
\hline & \\
\hline
\end{tabular}

TABLE VII. MAXIMUM VALUES OF HyPOTHESES

\begin{tabular}{|c|c|c|c|c|}
\hline & Area 0 & Area 1 & Area 2 & Area 3 \\
\hline & $\begin{array}{l}<3000 \\
\text { masl }\end{array}$ & $\begin{array}{l}3000 \text { a } 4000 \\
\text { masl }\end{array}$ & $\begin{array}{l}4001 \text { a } 4500 \\
\text { masl }\end{array}$ & $\begin{array}{l}>4500 \\
\text { masl }\end{array}$ \\
\hline Hypothesis 1 & \multirow{2}{*}{\multicolumn{4}{|c|}{ Unit of Measure ${ }^{\circ} \mathbf{C}$}} \\
\hline $\begin{array}{l}\text { Longer lasting } \\
\text { condition - EDS }\end{array}$ & & & & \\
\hline $\begin{array}{l}\text { Average annual } \\
\text { temperature }\end{array}$ & 15 & 10 & 5 & 0 \\
\hline Wind speed & 0 & 0 & 0 & 0 \\
\hline Ice overload & 0 & 0 & 0 & 0 \\
\hline EDS (\% Breaking pull) & 18 & 18 & 18 & 18 \\
\hline Hypothesis 2 & \multirow{2}{*}{\multicolumn{4}{|c|}{ Unit of Measure ${ }^{\circ} \mathbf{C}$}} \\
\hline Minimum temperature & & & & \\
\hline Minimum temperature & 5 & 0 & 0 & -10 \\
\hline Wind speed & 0 & 0 & 113 & 0 \\
\hline Ice overload & 0 & 0 & 0 & 0 \\
\hline$\%$ Breaking pull - ADSS & 51 & 51 & 51 & 51 \\
\hline Hypothesis 3 & \multirow{2}{*}{\multicolumn{4}{|c|}{ Unit of Measure ${ }^{\circ} \mathbf{C}$}} \\
\hline Maximum wind speed & & & & \\
\hline $\begin{array}{l}\text { Average annual } \\
\text { temperature }\end{array}$ & 10 & 5 & 0 & -5 \\
\hline Wind speed & 94 & 104 & 113 & 120 \\
\hline Ice overload & 0 & 0 & 0 & 0 \\
\hline$\%$ Breaking pull - ADSS & 51 & 51 & 51 & 51 \\
\hline Hypothesis 4 & \multirow{2}{*}{\multicolumn{4}{|c|}{ Unit of Measure ${ }^{\circ} \mathbf{C}$}} \\
\hline Maximum ice load & & & & \\
\hline Minimum temperature & 0 & 0 & -5 & -10 \\
\hline Wind speed & 0 & 0 & 0 & 0 \\
\hline Ice overload & 0 & 6 & 25 & 50 \\
\hline$\%$ Breaking pull - ADSS & 51 & 51 & 51 & 51 \\
\hline Hypothesis 5 & \multirow{2}{*}{\multicolumn{4}{|c|}{ Unit of Measure ${ }^{\circ} \mathbf{C}$}} \\
\hline $\begin{array}{l}\text { Maximum } \\
\text { temperature }\end{array}$ & & & & \\
\hline $\begin{array}{l}\text { Maximum temperature- } \\
\text { ADSS }\end{array}$ & 30 & 25 & 20 & 15 \\
\hline Wind speed & 0 & 0 & 0 & 0 \\
\hline Ice overload & 0 & 0 & 0 & 0 \\
\hline$\%$ Breaking pull - ADSS & 51 & 51 & 51 & 51 \\
\hline Hypothesis 6 & \multirow{2}{*}{\multicolumn{4}{|c|}{ Unit of Measure ${ }^{\circ} \mathbf{C}$}} \\
\hline Wind + ice & & & & \\
\hline $\begin{array}{l}\text { Average annual } \\
\text { temperature }\end{array}$ & 5 & 0 & -5 & -10 \\
\hline Wind speed & 50 & 52 & 56 & 61 \\
\hline Ice overload & 0 & 3 & 12 & 25 \\
\hline$\%$ Breaking pull - ADSS & 51 & 51 & 51 & 51 \\
\hline
\end{tabular}




\section{7) Formulas considered}

a) Equation of Change of State: The change of state of the cables for different spans and different environmental conditions is governed by the following cubic equation [18].

$T_{f}^{3}+T_{f}^{2} *\left[\frac{d^{2} W_{i}^{2} E \operatorname{Cos}^{3} \emptyset}{24 S \sigma_{i}}+\alpha\left(t_{2}-t_{1}\right) E \operatorname{Cos} \emptyset-\sigma_{i} S\right]$

$-\frac{d^{2} W_{f}^{2} E \operatorname{Cos}^{3} \emptyset}{24}=0$

$\operatorname{Cos} \emptyset=\frac{1}{\sqrt{1+\left(\frac{H}{D}\right)^{2}}}(17)$

Where:

$T_{f} \quad$ : Final horizontal draft $(\mathrm{kg})$

$d \quad$ : Vain (m)

$W_{i} \quad$ : Initial unit weight $(\mathrm{kg} / \mathrm{m})$

$W_{f} \quad$ : Final unit weight $(\mathrm{kg} / \mathrm{m})$

$t_{2} \quad$ : Conductor section $\left(\mathrm{mm}^{2}\right)$

$\sigma_{i} \quad$ : Initial unit horizontal force $\left(\mathrm{kg} / \mathrm{mm}^{2}\right)$

$t_{2} \quad$ : Final temperature $\left({ }^{\circ} \mathrm{C}\right)$

$t_{1} \quad$ : Initial temperature $\left({ }^{\circ} \mathrm{C}\right)$

$\alpha \quad$ : Coefficient of linear expansion $\left(1 /{ }^{\circ} \mathrm{C}\right)$

E : Elastic modulus $\left(\mathrm{kg} / \mathrm{mm}^{2}\right)$

$\frac{H}{D} \quad:=$ Ratio of unevenness/span

With the equation, the results of the mechanical calculation of the various environmental conditions that affect the fiber optic cable are obtained, they will be analyzed in zone B, Areas $0,1,2$ and 3 for the different state hypotheses previously described.

8) Wind pressure: The wind pressure has been determined according to what is indicated in the CNE, which indicates in rule 250.B and table 250-1-A, that the speed should be 94 $\mathrm{km} / \mathrm{h}$ for load zone B (moderate). To obtain the wind pressure, the formula of CNE rule 250.C is applied [3].

$P v=K * V^{2} * S f * A \ldots[3]$

Where:

Pv : Load in Newton

K : Pressure Constant

$K: 0.613$ for altitude up to 3000 masl.

$K: 0.455$ for altitude greater than 3000 masl.

$V \quad:$ Wind speed $\mathrm{m} / \mathrm{s}$

$S f \quad$ : Form factor (see Rules 251.A.2 y 252.B.2)

A : Projected area $\mathrm{m}^{2}$
With the equation, the results of the calculations of the horizontal wind loads or pressures due to the wind that are applied to the fiber optic cable are obtained in the areas where it is planned to install, according to the different hypotheses previously raised.

9) Distribution of structures with fiber optics: The following in the Fig. 3 graphically shows the typical distribution of ADSS fiber optic cable, located under the phase conductors of existing electrical networks.

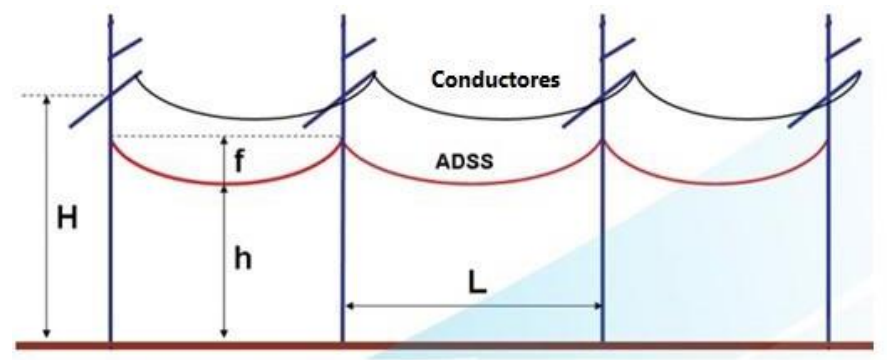

Fig. 3. Line of mean Voltage Line.

Where:

$\mathrm{H} \quad$ : Height of electrical structure

f : fiber optic arrowing

$\mathrm{H} \quad$ : Height of the optical fiber with reference to the ground

L : Span length

ADSS : Fiber Optic Cable

Conductors: Power line cable

10)Calculation methodology

a) Data entry: The analysis begins with the entry of information from the topographic survey and technical characteristics of the existing electrical network given in the data portfolio. The technical characteristics of the fiber optic cable of each span 250, 600 and 1200 are considered, such as: section, diameter, weight of the cable, breaking pull, elasticity modulus and coefficient of expansion [16]. Six state hypotheses are established that allow the simulation of the mechanical calculation of the cable in the most unfavorable scenario through the State Change Equation (ECE) [18].

b) Data reporting: The calculations of mechanical stresses of the fiber optic cable, analyzed in each state hypothesis, are shown in a report sheet. It is verified that in the most unfavorable scenario it does not exceed the maximum allowable tension defined by the manufacturer $(\leq 51 \%)$. Likewise, in each section analyzed, the gap with the maximum arrow is identified; for subsequent verification of compliance with the Minimum Safety Distance (MSD).

\section{Technical Studies of Electric Fields}

The purpose of the development of this study is to determine in an analytical way, the electric field levels produced by medium voltage lines, which are distributed in 47 districts within the Lima Region, the voltage levels presented 
by these power lines correspond to $10 \mathrm{kV}$ and $2.9 \mathrm{kV}$. The calculations to be carried out will have the purpose of verifying compliance with the levels of exposure to magnetic fields allowed by the CNE [3], the International Commission on Non-Ionizing Radiation Protection (ICNIRP) [19], and IEEE Standards Association, "IEEE 1222-2019 - IEEE Standard for Testing and Performance for ADSS Fiber Optic Cable for Use on Electric Utility Power Lines," Nov. 07, 2019 [13].

The electric power transmission line produces electric field emissions, which vary according to the characteristics and disposition of the conductors [19]. Theses emissions must respect the maximum permissible exposure limit values established in National and International Regulations.

For the case of this study, the analysis of electric fields was carried out at the installation height of the fiber optic cable, in a transverse direction to the axis of the line up to the limit of the easement strip, as established in Section 21, rule 212 of the CNE.

As indicated in Resolución Ministerial $N^{\circ}$ 368-2011MTC/03 "Especificaciones Técnicas para el Tendido de Fibra Óptica en Redes de Energía Eléctrica y de Hidrocarburo"; section 2.4; rule 2.4.1 [15]. For aerial applications, in the case of ADSS [13], the following should be considered:

- Strong electric fields, overhead cables without metal parts installed in the high-voltage and medium-voltage environment of power transmission lines are subject to the influence of the electric field of these power lines, which can lead to phenomena such as corona effect, arcing or conducting path in cable cover [20].

- To avoid damage, the fiber optic cable must be installed in electric transmission lines considering values where the magnetic electric field is minimal, likewise it is important to use special cable covering materials depending on the level of electric/magnetic field present in the work area.

11)Characteristics of the medium voltage line: For the analysis of medium voltage lines, the approximate distances of the existing electrical networks in the project area are presented, which are distributed in $325 \mathrm{~km}$ of electrical network belonging to the ENEL company, $10.24 \mathrm{~km}$ of electrical network belonging to the company COELVISAC and $207.76 \mathrm{~km}$ of electrical network belonging to the company ADINELSA.

a) Installation Distance of Fiber Optic Cable: The vertical safety distance between conductors and communication cables should not be less than indicated in table 233-1 of the CNE [3]. For the installation of the fiber optic cable, a minimum vertical distance of $1.80 \mathrm{~m}$ in medium voltage line and $0.60 \mathrm{~m}$ in low voltage line must be considered. To comply with the provisions of the CNE, section 23, a safety distance of $2.30 \mathrm{~m}$ has been considered between the phase conductor and the fiber optic cable, in the same way as shown below in Fig. 4.

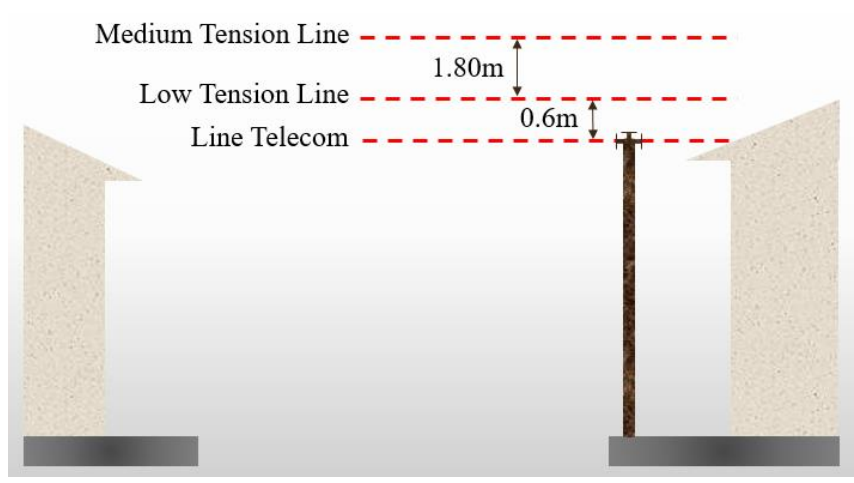

Fig. 4. Safety Distances from Installation of Medium and Low Voltage Networks to Communications Networks.

12)Electric field analysis: The electric field describes the force exerted on a unit of electric charge. It is represented by lines of force that surround the electrical device. Electric fields are produced due to the presence of electric charges, regardless of their state of motion [21]. A charge at a given point produces an electric field in all directions, with a spherical symmetry pattern. In an electric transmission line, it produces an electric field around its entire path, giving rise to a model with cylindrical symmetry, in the same way as shown below in Fig. 5 [6].

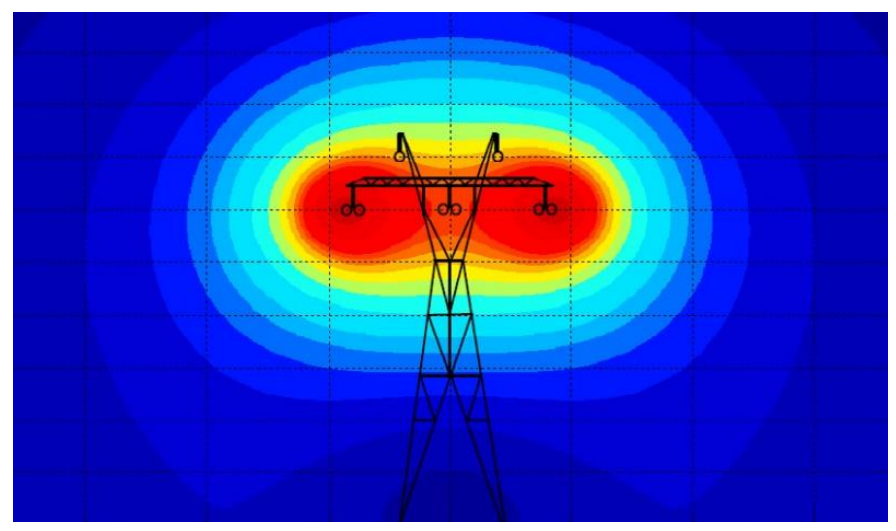

Fig. 5. Electric Field Generated by Electric Cables.

a) Tracking effect: The use of existing structures of electrical power networks for the installation of fiber optic cables is quite common, which generates significant savings compared to other forms of installation [15]. However, although the cost-benefit ratio is quite interesting, this methodology also involves some difficulties. A quite common problem is the erosion of the outer covering of the optical cables caused by the tracking effect, due to the proximity with the high voltage cables and the existing electric field [6]. Explaining better: the exposure of the cable to the electrical potential generated by the power transmission line, added to the effect of bad weather (rain, solar radiation, etc.) and environmental pollution, results in the emergence of conductive regions on the surface optical cables. 
Under these conditions, when two humid regions delimit an intermediate dry region, the emergence of a potential gradient occurs. The higher the level of pollution in the environment, the more intense the electric discharge generated between the humid regions, since the pollution particles deposited on the surface of the cable increase the level of electric current now of discharge. The small and constant electrical discharges that arise between the two humid regions, finally, cause the heating, the breaking of the polymeric chains and other chemical reactions in the material that constitutes the outer cover of the optical cables. This effect is accompanied by light scintillations (leakage currents) and ends up forming a "trace", which is a permanent conductive path that appears on the surface of the insulating material. This is the phenomenon of the "Tracking Effect" also known as "Dry Band Arcing" [22], which ends up damaging the material of the outer cover of the optical cable, totally compromising its protection, as can be seen in Fig. 6 [23].

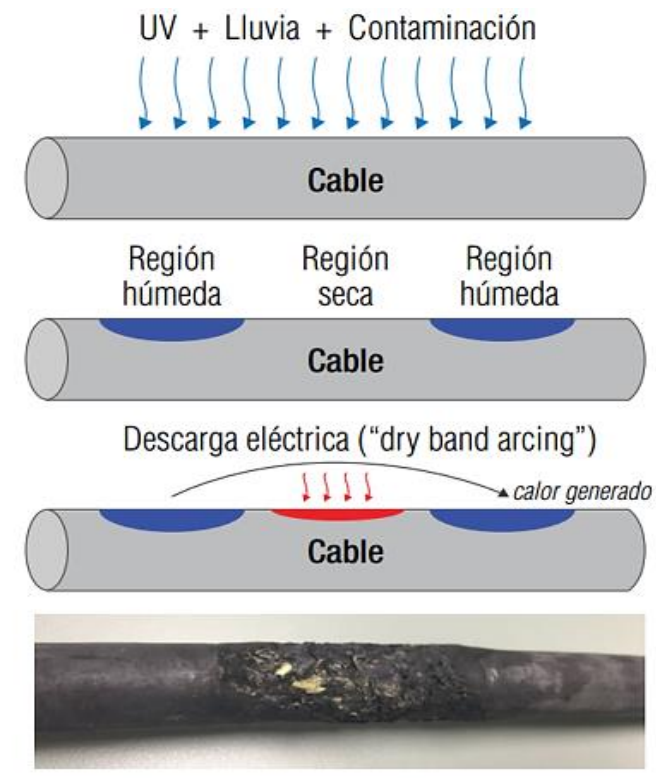

Fig. 6. Optical Cable Degraded by the Tracking Effect.

In accordance with Standard IEEE 1222-2019, the way to verify the tracking effect and the resistance of its cover to erosion are indicated in the tests on ADSS cables, for cables with Class A cover, no electrical tests are required. A cable with a Class A cover, it is understood that it will be used when the high voltage line is below $110 \mathrm{kV}$ and therefore the level of electrical stress will not exceed $12 \mathrm{kV}$ of space potential acting on the cable cover [13]. For ADSS cables with Class B cover, it implies that the cable may be used in high voltage lines above $110 \mathrm{kV}$ and therefore require electrical tests, it corresponds to a level of electrical stress that exceeds $12 \mathrm{kV}$ of space potential acting on the cable cover.

13)Calculation methodology: The electric field calculations were developed using the Electric Field of Transmission Lines (EFT) calculation software, an application of the Electric Power Research Institute (EPRI) [24].

\section{RESULTS}

This section will show the results of the studies carried out, such as the mechanical loads and electric fields to which the fiber optic cables will be exposed when installed on existing electrical network lines.

\section{A. Result of the Study of Mechanical Loads}

The results obtained in the mechanical calculation of the fiber optic cable, the same ones that were analyzed in zone B, areas $0,1,2$ and 3 for the different state hypotheses, as shown in the following report, where it is concluded that the fiber optic cable to be installed is below the maximum allowable tension given by the manufacturer, so its installation is feasible. The results of the modeling of the mechanical calculation of ADSS fiber optic cable are shown in the following Tables VIII and IX, which for calculation purposes only the most unfavorable scenarios have been considered.

\section{TABLE VIII. MECHANICAL LOADS OF THE FiBER OPCTIC CABLECARGAS MECÁNICAS DEL CABLE DE FIBRA OPTICA}

\begin{tabular}{|c|c|c|c|c|}
\hline \multirow{7}{*}{$\begin{array}{l}\text { Study of } \\
\text { Mechanical } \\
\text { Loads of } \\
\text { Fiber Optic } \\
\text { Cable }\end{array}$} & Ring & $\mathrm{C} 1$ & $\mathrm{C} 1$ & $\mathrm{C} 2$ \\
\hline & Section & $\begin{array}{l}\text { S109 - } \\
\text { copa }\end{array}$ & $\begin{array}{l}\text { Oyon - } \\
\text { Churin }\end{array}$ & $\begin{array}{l}\text { Sayan - } \\
\text { Humaya }\end{array}$ \\
\hline & Item & $9-10$ & $154-185$ & $92-93$ \\
\hline & East & 273157 & 295260 & 255096 \\
\hline & North & 8839097 & 8806820 & 8767631 \\
\hline & $\begin{array}{l}\text { Altitude } \\
\text { (masl) }\end{array}$ & 2823.00 & 2379.00 & 586.48 \\
\hline & Span & 600 & 250 & 1200 \\
\hline Span & $\mathbf{a}(\mathbf{m})$ & 390.39 & 213.86 & 84.01 \\
\hline Unevenness & $\mathbf{h}(\mathbf{m})$ & -141.00 & -2.00 & -0.82 \\
\hline Area & Area & AREA0 & AREA0 & AREA0 \\
\hline \multirow{3}{*}{$\begin{array}{l}\text { Hypothesis } \\
1\end{array}$} & Shot H(kg) & 407.97 & 229.74 & 773.56 \\
\hline & TMax (kg) & 444.65 & 230.33 & 773.70 \\
\hline & Arrow (m) & 7.00 & 3.31 & 0.20 \\
\hline \multirow{3}{*}{$\begin{array}{l}\text { Hypothesis } \\
2\end{array}$} & Shot H(kg) & 409.91 & 232.38 & 774.86 \\
\hline & TMax (kg) & 446.72 & 232.96 & 775.00 \\
\hline & Arrow (m) & 6.97 & 3.27 & 0.20 \\
\hline \multirow{3}{*}{$\begin{array}{l}\text { Hypothesis } \\
3\end{array}$} & Shot H(kg) & 780.23 & 439.69 & 815.02 \\
\hline & TMax (kg) & 881.48 & 444.86 & 815.83 \\
\hline & Arrow (m) & 15.76 & 7.71 & 0.73 \\
\hline \multirow{3}{*}{$\begin{array}{l}\text { Hypothesis } \\
4\end{array}$} & Shot H(kg) & 410.89 & 233.71 & 775.51 \\
\hline & TMax (kg) & 447.75 & 234.29 & 775.65 \\
\hline & Arrow (m) & 6.95 & 3.25 & 0.20 \\
\hline \multirow{3}{*}{$\begin{array}{l}\text { Hypothesis } \\
5\end{array}$} & Shot H(kg) & 405.07 & 225.84 & 771.62 \\
\hline & TMax (kg) & 441.58 & 226.43 & 771.76 \\
\hline & Arrow (m) & 7.05 & 3.37 & 0.20 \\
\hline \multirow{3}{*}{$\begin{array}{l}\text { Hypothesis } \\
6\end{array}$} & Shot H(kg) & 409.91 & 232.38 & 774.86 \\
\hline & TMax (kg) & 453.50 & 233.69 & 775.07 \\
\hline & Arrow (m) & 10.80 & 5.18 & 0.29 \\
\hline
\end{tabular}


TABLE IX. MAXIMUM STRESS OF THE FIBER OPTIC CABLE

\begin{tabular}{|l|l|l|l|l|}
\cline { 2 - 5 } \multicolumn{1}{c|}{} & Section & Oyon - Churin & S109 - Copa & Sayan - Humaya \\
\cline { 2 - 5 } \multicolumn{1}{c|}{} & Cluster & 1 & 1 & 2 \\
\hline \multirow{2}{*}{$\begin{array}{l}\text { Maximum } \\
\text { Effort }(\mathrm{kg})- \\
\text { Calculated }\end{array}$} & Span 250 & 444.86 & 899.67 & 408.36 \\
\cline { 2 - 5 } & Span 600 & 916.47 & 1671.76 & 1487.31 \\
\cline { 2 - 5 } & Span 1200 & $1,663.40$ & & \\
\hline $\begin{array}{l}\text { Breaking Load } \\
\text { (kg) - } \\
\text { Established by } \\
\text { the } \\
\text { Manufacturer }\end{array}$ & Span 250 & $1,276.36$ & $1,276.36$ & $1,276.36$ \\
\cline { 2 - 5 } & Span 600 & $2,266.50$ & $2,266.50$ & $2,266.50$ \\
\hline \multirow{2}{*}{$\begin{array}{l}\text { Verification\% } \\
\text { of Maximum } \\
\text { Span Effort }\end{array}$} & Span 1200 & $4,297.57$ & $4,297.57$ & $4,297.57$ \\
\cline { 2 - 5 } & Span 600 & $40 \%$ & $45 \%$ & $32 \%$ \\
\cline { 2 - 5 } & Span 1200 & 0.39 & $39 \%$ & $35 \%$ \\
\hline Permitted $\rightarrow$ & \multicolumn{2}{|l}{} & $\geq 51 \%$ & $\geq 51 \%$ \\
\hline
\end{tabular}

\section{B. Result of the Study of Electric Fields}

From the results obtained, for the conductor arrangements of the 10 and $22.9 \mathrm{kV}$ medium voltage lines, it is concluded that the ADSS type fiber optic cable to be installed complies with the provisions of the IEEE 1222-2019 standard, title 5 ADSS Application Requirements and recommendations", item 5.9 "Electrical Requirements (electric fields, corona effect and contamination)", as well as the provisions of the CNE, section 21, rule 212 "Induced Voltages - Electric Fields"[1], by the following considerations:

1) The ADSS fiber optic cable to be installed in the most unfavorable scenarios is immersed in an electric field lower than that established in the CNE $(<8.3 \mathrm{kV} / \mathrm{m})$ [3]; thus; its installation does not represent a greater population risk, nor is it necessary to install an ADSS anti tracking cable because it presents potentials less than $10 \mathrm{kV}$.

2) The contamination indexes where the installation of the ADSS fiber optic cable is projected, generally presents a level of light contamination levels I and II according to classification according to the International Electrotechnical Commission (IEC) TS 60815 -4: 2016, because they are:

a) Zones without large industries do not produce high polluting smoke;

b) Areas with low and/or moderate population density;

c) Agricultural areas subject to frequent winds and rains;

d) Areas distant from the sea $>10 \mathrm{~km}$.

According to the reports obtained from the analysis of the electric field (potential gradient and electric potential) and environmental conditions of the fiber optic cable installation areas, it is argued that the evaluation of dry band arcing does not apply (dry band arcing), or corona discharges, as stipulated in the annexes of the IEEE 1222-2019 standard.

\section{Evidence of Fiber Optic Installation}

In Fig. 7, you can see the optical fiber installed on poles, where the recommendations set forth in the present investigation were followed, thus obtaining the installation of the optical fiber for the various geographical and climatological areas that owns the Lima-Peru region.

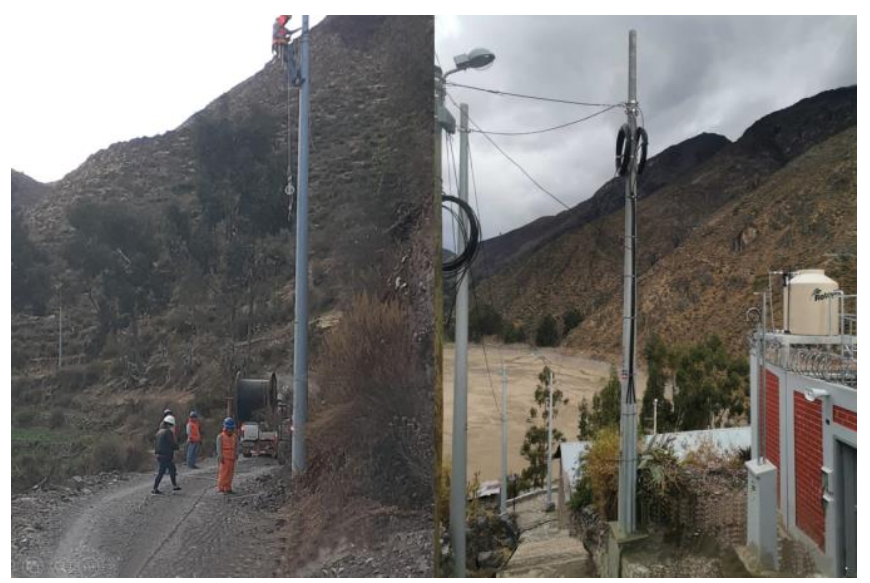

Fig. 7. Optical Fiber Installed in the Lima-Peru Region.

\section{DiscusSIONS}

In [5], his research article Minimum technical specification of optical fiber for the construction of the National Backbone Network, he does not consider the climatic factors and geographical areas where the optical fiber will be installed, being a variable of interest for the present research work, considering that Peru has diverse and adverse geographic and climatic conditions, otherwise it occurs in the present research work, in which the geographic zones and climatological area are presented and described, where the optical fiber will be installed, due to the variant climate possessed by the various regions of Peru, especially the Lima region, which is part of the research analysis.

In [2], presents, in his research article Development of a software application to automate the design of optical links and its application in a link for the Minas - San Francisco, Ecuador power plant, the climatological factors are not considered and geographical areas in their development, this being a fundamental characteristic in the development of the current research, due to the fact that when transporting high information capacity, and even more so in the case of trunk fiber optic links, it is essential to consider these factors for the optimal functioning of the network, thus minimizing the cost of maintenance and loyalty of the service.

Taking into account the thesis [25], Design of a transport network over fiber optics to increase the broadband of the regions: Arequipa, Moquegua, Puno and Tacna, where he proposes the solution of enabling broadband, speeds higher than $256 \mathrm{kbit} / \mathrm{s}$ [26], on an existing overhead electrical network infrastructure, considering that the aforementioned regions are located in rugged geographical areas, areas with difficult to access and extreme climates, factors such as mechanical loads and electrical fields are not considered, which if they are considered as a fundamental part in the present research work, given that when transmitting high information capacity the installed or installed fiber optic has to overcome all geographical and environmental conditions.

As stated by [7], in his thesis, Design of a Broadband Telecommunications Network for the San Martín Region, he refers to the fact that the fiber optic cable will be installed on electricity network poles, however not describes the effects of 
electric fields, nor the minimum safety distance, as recommended by the $\mathrm{CNE}$ [3]. The opposite is the case in the present research work, where if these essential factors are considered, such as the electric field produced by high, medium, and low voltage power lines, which minimizes the useful life of the optical fiber, in addition to safeguarding the Physical integrity of the engineers when carrying out the installation, the minimum safety distance between the electrical conductor and the optical fiber is considered.

Based on the citations of the previous research work of the region, no article was found that takes as a reference the $\mathrm{CNE}$, for the development of their research proposals, where they describe and consider the area and geographical area, study of loads mechanical and electric fields as indispensable factors for the analysis and choice of the type of fiber optic cable to use for the installation, knowing that Lima region of Peru, has a great diversity of factors and climatic and geographical conditions.

\section{CONCLUSIONS}

It is concluded after the research work carried out that the best option for choosing the type of optical fiber for installation in the Lima region, Peru, is the one that follows the ITU G.652.D standard, due to its special resistance characteristics to the mechanical loads and electric fields produced by the area, they do not affect the cable, thus minimizing maintenance costs and maximizing the durability, efficiency and quality of service to end users, generating greater profitability for companies, which unlike using cables of Optical fiber without conducting the aforementioned studies for the choice of cable type, does not guarantee durability or continuity of service and thus the loss of customer users.

It is concluded that based on the analysis and results obtained in the mechanical calculations of the fiber cable of the FiberHome company manufactured under the characteristics and recommendations of the ITU-T G.652.D, it complies with the maximum permissible stresses associated with the cable, the same that were given by the manufacturer, considering the geographic location, weather characteristics, wind pressure and ice, to be installed in zone B, areas 0,1,2 and 3, of the Lima region, Peru, on network lines electrical.

It is concluded that if all the companies that install fiber optic cables for high capacity links on existing medium and low voltage electrical network lines, would carry out the implementation under the recommendations indicated in the present research work, such as mechanical calculations of maximum allowable stress and electric fields, not only would increase the useful life of the optical fiber, but also the cost of maintenance would be reduced, thus avoiding breakdowns and failures in the operation of the network, which in many cases incur high costs for repair.

As a future research project, I recommend carrying out an analysis on the resistance to pollution of optical fibers according to the IEEE 1222-2019 standard for use in power lines, since the optical fiber when installed near environments of in where there are industrial areas, volcanic areas and areas with high salinity, particles such as sand and salt are deposited on the surface of the cable and this could damage the optical fiber over time and affect operation.

\section{REFERENCES}

[1] L. Hinojosa Gomez, "Selected Topics of Optical Fiber," Universidad Autónoma del Estado de Hidalgo, Pachuca-México, 2007.

[2] W. Gómez Pauta, "Development of a software application to automate the design of optical links and their application in a link for the Minas San Francisco power plant," Universidad del Azuay, Cuenca - Ecuador, 2017.

[3] Dirección General de Electricidad, "National Code of ElectricityUtilization,” Lima-Perú, $2006 . \quad$ Available: http://intranet2.minem.gob.pe/web/cafae/Pdfs/CNE.PDF.

[4] L. S. Criollo Caizaguano, "Design of a convergent fiber optic network to interconnect the Campus of the University of the Americas," Quito / PUCE / 2015, Quito-Ecuador, 2017.

[5] W. Azurza Neyra, "Minimum Technical Specification of Optical Fiber for the construction of the National Backbone Network," Lima-Perú, 2016. Available: https://es.slideshare.net/wazurza/paper-especificacintcnica-mnima-de-fibra-ptica-para-la-construccin-de-la-red-dorsalnacional.

[6] Furukawa Electric LatAm, "ADSS Optical Cables resistant to the tracking effect," Furukawa Electric, Dec. 22, 2017. https://www.furukawalatam.com/es/conexion-furukawa-detalles/cablesopticos-adss-resistentes-al-efecto-tracking.

[7] Fiber Optic Association, "FOA Reference Guide To Fiber Optics," FOA, 2017. https://www.foa.org/ESP/Cable.htm.

[8] L. Claudio Bedregal, "Design of a Broadband Telecommunications Network for the San Martín Region," Pontificia Universidad Católica del Perú, Lima-Perú, 2016.

[9] International Telecommunication Union, "G.652 : Characteristics of a single-mode optical fibre and cable," ITU, 2017. https://www.itu.int/rec/T-REC-G.652-201611-I/en.

[10] E. D. López Polo, "Design of a fiber optic network for the implementation of broadband service in Coishco (Ancash)," Universidad de Ciencias y Humanidades, Lima-Perú, 2016.

[11] C. Barbut, "Next level for Fiber Optic Projects deployments," in Proceedings of the 11th International Conference on Electronics, Computers and Artificial Intelligence, ECAI 2019, Jun. 2019, pp. 1-3, doi: 10.1109/ECAI46879.2019.9042045.

[12] C. Teneco, "FOA Reference Guide To Fiber Optics," FOA, 2017. https://foa.org/ESP/Fibra_optica.htm.

[13] IEEE Standards Association, “1222-2019 - IEEE Standard for Testing and Performance for All-Dielectric Self-Supporting (ADSS) Fiber Optic Cable for Use on Electric Utility Power Lines," IEEE Xplore, Mar. 31, 2020. https://ieeexplore.iee.org/document/9052820.

[14] IEEE, "IEEE 1222-2019 - IEEE Standard for Testing and Performance for All-Dielectric Self-Supporting (ADSS) Fiber Optic Cable for Use on Electric Utility Power Lines," IEEE Standards Association, Nov. 07, 2019. https://standards.ieee.org/content/ieee-standards/en/standard/12222019.html.

[15] Ministerio de Transportes y Comunicaciones, Technical Specifications for the Laying of Optical Fiber in Electric Power and Hydrocarbon Networks, Perú. Lima-Perú: Resolución Ministerial № 368-2011MTC/03, May 30, 2011, 2011, pp. 1-16.

[16] FiberHome Technologies, “Optical Fiber \& Cable," FiberHome, 2019. http://www.fiberhome.com/.

[17] C. Barbut, "Fiber Optic Deployments in Romania between Metropolitan Fiber Optic Networks and Indoor Fiber Optic Infrastructure," in Proceedings of the 10th International Conference on Electronics, Computers and Artificial Intelligence, ECAI 2018, Apr. 2019, pp. 1-3, doi: 10.1109/ECAI.2018.8679021.

[18] C. Castillo, "Design of Transmission Lines: Don Bosco University | Electric power transmission | Distribution (commercial)," Soyapango-El Salvador, 2016. Available: https://es.scribd.com/document/305312619/ Clase-1-Diseno-de-Lineas-TX. 
[19] ICNIRP International Commission on Non-Ionizing Radiation Protection, "Guidelines for limiting exposure to electromagnetic fields (100 kHz to $300 \mathrm{GHz}$ )," Health Physics, May 01, 2020. https://www.icnirp.org/en/activities/news/news-article/rf-guidelines2020-published.html.

[20] P. Barcik, P. Munster, P. Dejdar, T. Horvath, and J. Vojtech, "Measurement of Polarization Transient Effects Caused by Mechanical Stress on Optical Fiber," in 2019 International Workshop on Fiber Optics in Access Networks, FOAN 2019, Sep. 2019, pp. 26-28, doi: 10.1109/FOAN.2019.8933658.

[21] IEEE, "IEEE PC95.3 - IEEE Draft Recommended Practice for Measurements and Computations of Electric, Magnetic and Electromagnetic Fields with Respect to Human Exposure to Such Fields, 0 Hz-300 GHz," IEEE Standards Association, Feb. 06, 2016. https://standards.ieee.org/project/C95_3.html.

[22] OFIL Systems, "ADSS Fiber Optic Cables in Overhead Transmission lines and the Corona phenomenon - OFIL - Daytime Corona Cameras," OFIL Systems, 2018. https://ofilsystems.com/articles/adss-dry-bandarcing/.
[23] GL-Technology, "Opgw Cable Factory - China Opgw Cable Manufacturers \& Suppliers," GL-Technology Manufacturer \& Exporter, 2017. https://www.gl-fiber.com/products-opgw-cable/?gclid=CjOKCQ jwrsGCBhD1ARIsALILBYokSxfHoxtcvFyf-NqN-iut-ZpylxMAjjtI1MIUWQsAcYcNd7sh_IaAvKWEALw_wcB.

[24] P. Taheri, B. Kordi, and A. M. Gole, "Electric field radiation from an overhead transmission line located above a lossy Ground," 2008, doi: 10.1109/UPEC.2008.4651634.

[25] A. Nuñez Pacheco, "Design of a Transport Network on Optical Fiber to Increase the Broadband of the Regions: Arequipa, Moquegua, Puno and Tacna," Universidad Nacional de San Agustín de Arequipa, ArequipaPerú, 2018.

[26] M. V. Alderete, "Broadband adoption in Latin American countries: does geographic proximity matter?," Probl. del Desarro. Rev. Latinoam. Econ., vol. 50, no. 198, pp. 31-56, May 2019, doi: 10.22201/iiec.20078951e.2019.198.67411. 